\title{
ХИМИЧЕСКОЕ ЗАГРЯЗНЕНИЕ ПОЧВЫ В РАЙОНАХ НЕСАНКЦИОНИРОВАННЫХ СВАЛОК Г. УЛАН-УДЭ
}

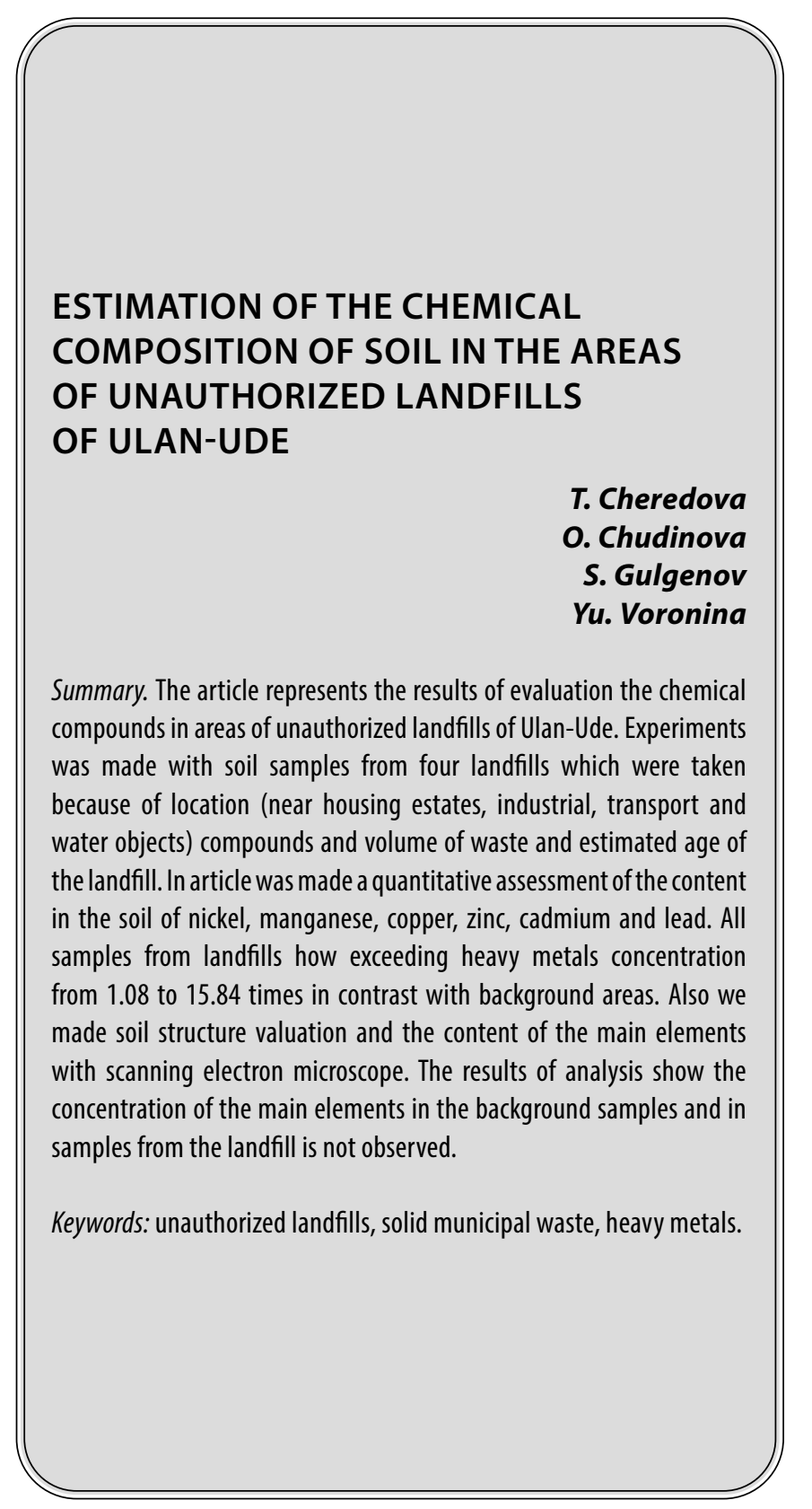

\section{Введение}

$\Pi$ очвы всех урбанизированных территорий подвержены значительной антропогенной нагрузке. Причинами тому являются изъятие земельных участков в длительное пользование для строительства производственных и жилых объектов, выбросы загрязняющих веществ в атмосферу в ре-
Чередова Татьяна Викторовна

Старший преподаватель, ФГБОУ ВО «ВосточноСибирский государственный университет технологий и управления» (2. Улан-Удэ) cheredova-tv@yandex.ru

Чудинова Ольга Николаевна

К.б.н., дочент, ФГБОУ ВО «Восточно-Сибирский государственный университет технологий и управления» (2. Улан-Удэ) chudinova1980@inbox.ru

Гулгенов Сергей Жаргалович

К.б.н., старший преподаватель, ФГБОУ ВО «Восточно-Сибирский государственный университет технологий и управления» (2. Улан-Удэ) gulgenov-s@mail.ru

Воронина Юлия Сергеевна Преподаватель, ФГБОУ ВО «Восточно-Сибирский государственный университет технологий и управления» (2. Улан-Удэ) u_voronina96@mail.ru

Аннотация. В статье представлены результаты оценки химического состава почвы в районах несанкционированных свалок г. Улан-Удэ. Эксперимент проводился с образцами почвы с четырех свалок, основными критериями выбора которых являлись их месторасположение (близость к жилым домам, промышленным, транспортным объектам, водным объектам), ориентировочный состав и объем накопленных отходов, предположительный «возраст» свалки. В работе проведена количественная оценка содержания в почве никеля, марганца, меди, цинка, кадмия и свинца. Во всех исследуемых пробах почвы со свалок наблюдается превышение концентрации тяжелых металлов от 1,08 до 15,84 раз по сравнению с фоновыми пробами. Также была проведена оценка структуры почвы и содержания основных элементов в ней с помощью растрового электронного микроскопа, анализ результатов которой показал, что значительного изменения концентрации основных элементов в фоновых пробах и в образцах с территории свалок не наблюдается.

Ключевые слова: несанкционированная свалка, твердые коммунальные отходы, тяжелые металлы.

зультате деятельности промышленных предприятий и транспорта, устройство водонепроницаемых покрытий проездов, площадок и тротуаров [10]. В идеале оставшаяся часть открытых грунтовых покрытий должна быть использована для создания зеленых насаждений и лесопарковых зон, однако современной тенденцией многих малых городов России, в том числе и г. Улан-Удэ, является хаотичный рост несанкциониро- 
ванных свалок на грунтовой местности. Компоненты TKO, накопленных на свалках под действием атмосферных осадков могут мигрировать в почву, изменяя тем самым ее буферную способность, физические свойства, микробиологические, паразитологические показатели и химический состав почв. Поэтому при разработке рекомендаций по комплексному использованию загрязненных территорий, направленных на их фиторемедиацию, следует изучить химический состав почв.

\section{Шель исслеАования}

Изучение химического состава почвы в районах несанкционированных свалок г. Улан-Удэ.

\section{Объекты и методы исслеАования}

Объектами исследования являлись образцы почвы с несанкционированных свалок на территории г. Улан-Удэ. Для оценки химического загрязнения почвы в районах несанкционированных свалок был проведен анализ миграции токсичных элементов в почву из состава отходов. Для этого были выбраны 4 несанкционированные свалки на территории г. Улан-Удэ (рецепторные точки №№ 1-3, 6) [11]. Рецепторная точка № 1. Свалка п. Батарейка, Советский район г. Улан-Удэ. Свалка площадью 375 м², размещена на участке с супесчаным типом почв с разреженной растительностью. Особенностью свалки является ее возраст, который, по словам местных жителей, составляет около 20 лет. Свалка за это время не убиралась. По результатам визуального осмотра количество накопленных на свалке отходов около 90 м³. На свалке накоплены коммунальные отходы, отходы садоводческих хозяйств, частично не крупногабаритные строительные отходы (кирпич, шифер).

Рецепторная точка № 2. Свалка п. Кирзавод, Железнодорожный район г. Улан-Удэ. Свалка площадью 70 м² размещена на участке с каштановым типом почв с хорошо развитой растительностью. Особенностью свалки является ее близость к границе промплощадки ТЭЦ-1. Свалка расположена в санитарно-защитной зоне предприятия, образована вокруг контейнерной площадки. Контейнерная площадка оборудована водонепроницаемым покрытием, имеет ограждение с трех сторон, на ней размещены стандартные металлические контейнеры объемом 0,75 м³ в количестве двух штук, отходы из которых периодически вывозятся, однако грунтовая территория вокруг площадки от мусора не очищается. По результатам визуального осмотра количество накопленных на свалке отходов около $21 \mathrm{M}^{3}$. Компонентный состав накопленных отходов представлен в основном коммунальным мусором, источником которого является население, проживающее в соседнем общежитии.
Рецепторная точка № 3. Свалка п. Восточный, Железнодорожный район г.Улан-Удэ. Свалка площадью

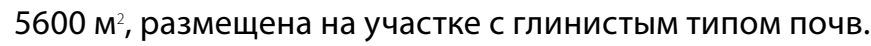
Свалка образована, прежде всего, компонентами строительного мусора (золошлаковые отходы, древесина, лом бетона, цемента), крупногабаритными отходами (мебель), а также коммунальными отходами, которые «рассеяны» по всей территории свалки. По результатам визуального осмотра свалка подвергалась горению. На некоторых участках свалки наблюдаются явления вторичной экологической сукцессии, которые проявляются в виде формирования плодородного слоя и восстановлении растительного слоя степного биоценоза. По результатам визуального осмотра количество

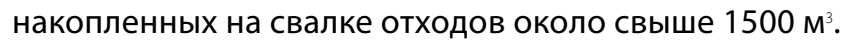

Рецепторная точка № 6. Свалка п. Сосновый, Октябрьский район г. Улан-Удэ. Свалка площадью 600 м², размещена на участке с песчаным типом почв. По компонентному составу накопленных отходов выбранная свалка аналогична рецепторной точке № 1 (свалка п. Батарейка), однако данная свалка используется местными жителями не только для складирования TKO, но также для слива жидких бытовых отходов, кроме того, верхний слой свалки периодически срезается и вывозится на захоронение. По результатам визуального осмотра количество накопленных на свалке отходов на момент

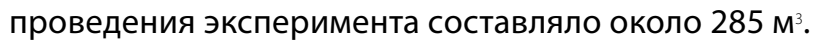

Для отбора проб каждая исследуемая свалка была условно вписана в окружность, по радиусу которой были отобраны три точки: точка отбора проб № 3 центр свалки (центр окружности); точка отбора проб № 1 - окраина свалки (граница окружности); точка отбора проб № 2 - середина свалки (посередине между точками № 1 и № 3). Кроме того, для каждой свалки была выбрана фоновая точка - участок с подобным типом почв, не загрязненный отходами. Пробы были отобраны в соответствии с существующими требованиями[6]. Точечные пробы отбирались на пробной площадке методом конверта. Для химического анализа объединенные пробы составлялись не менее чем из пяти точечных проб, взятых с одной пробной площадки. Масса каждой объединенной пробы - 1-1,2 кг.

Количественную оценку содержания в почве тяжелых металлов проводили с применением атомно-абсорбционного метода с плазменной атомизацией на атомно-абсорбционном спектрометре Spectr AA 240 (РД 52.18.191-89). Оценка структуры почвы и содержания основных элементов проводилась с помощью растрового электронного микроскопа JSM-6510LV JEOL, с привлечением Центра коллективного пользования «Прогресс» Восточно-Сибирского государственного университета технологий и управления. 
Таблица 1. Количественная оценка содержания тяжелых металлов в почвах

\begin{tabular}{|c|c|c|c|c|c|c|}
\hline \multirow{3}{*}{$\begin{array}{l}\text { Наименование } \\
\text { элемента }\end{array}$} & \multicolumn{5}{|c|}{ Концентрация тяжелого металла, мг/кг } & \multirow{3}{*}{$\begin{array}{l}\text { ПДК, } \\
\text { мг/кг }\end{array}$} \\
\hline & \multirow[b]{2}{*}{$\begin{array}{l}\text { Фоновая } \\
\text { точка }\end{array}$} & \multicolumn{4}{|c|}{ Точки отбора проб на свалке } & \\
\hline & & Точка № 1 & Точка № 2 & Точка № 3 & $\begin{array}{l}\text { Среднее } \\
\text { значение }\end{array}$ & \\
\hline \multicolumn{7}{|c|}{ Рецепторная точка № 1} \\
\hline Никель & $0,33 \pm 0,05$ & $0,80 \pm 0,20$ & $0,45 \pm 0,11$ & $0,54 \pm 0,14$ & $0,6 \pm 0,15$ & 20 \\
\hline Марганец & - & - & - & - & - & 1500 \\
\hline Медь & $0,91 \pm 0,23$ & $2,74 \pm 0,69$ & $2,50 \pm 0,63$ & $1,39 \pm 0,35$ & $2,21 \pm 0,56$ & 33 \\
\hline Цинк & $9,20 \pm 2,30$ & $86,0 \pm 21,5$ & $52,7 \pm 13,2$ & $192,8 \pm 48,2$ & $110,5 \pm 27,63$ & 55 \\
\hline Кадмий & 0,25 & $0,20 \pm 0,05$ & $0,14 \pm 0,04$ & $0,19 \pm 0,05$ & $0,18 \pm 0,05$ & 0,5 \\
\hline Свинец & $2,30 \pm 0,56$ & $3,11 \pm 0,78$ & $4,53 \pm 1,13$ & $5,5 \pm 1,4$ & $4,38 \pm 1,10$ & 32 \\
\hline \multicolumn{7}{|c|}{ Рецепторная точка № 2} \\
\hline Никель & $0,29 \pm 0,07$ & $0,14 \pm 0,03$ & - & $0,16 \pm 0,04$ & $0,15 \pm 0,04$ & 20 \\
\hline Марганец & $17,44 \pm 4,36$ & $16,44 \pm 4,11$ & $7,67 \pm 1,92$ & $13,44 \pm 3,36$ & $12,52 \pm 3,13$ & 1500 \\
\hline Медь & $1,02 \pm 0,26$ & $2,03 \pm 0,51$ & $1,07 \pm 0,27$ & $1,49 \pm 0,37$ & $1,53 \pm 0,38$ & 33 \\
\hline Цинк & $54,84 \pm 13,71$ & $16,65 \pm 4,16$ & $6,72 \pm 1,68$ & $16,63 \pm 4,16$ & $13,33 \pm 3,33$ & 55 \\
\hline Кадмий & $0,40 \pm 0,10$ & 0,25 & 0,25 & 0,25 & 0,25 & 0,5 \\
\hline Свинец & $5,69 \pm 1,42$ & $7,42 \pm 1,85$ & $6,47 \pm 1,62$ & $5,51 \pm 1,38$ & $6,47 \pm 1,62$ & 32 \\
\hline \multicolumn{7}{|c|}{ Рецепторная точка № 3} \\
\hline Никель & - & - & $0,47 \pm 0,12$ & $0,59 \pm 0,15$ & $0,53 \pm 0,14$ & 20 \\
\hline Марганец & $4,29 \pm 1,07$ & $9,64 \pm 2,41$ & $32,5 \pm 8,13$ & $44,2 \pm 11,05$ & $28,78 \pm 7,2$ & 1500 \\
\hline Медь & $0,50 \pm 0,13$ & $0,55 \pm 0,14$ & $0,25 \pm 0,24$ & $0,82 \pm 0,21$ & $0,54 \pm 0,2$ & 33 \\
\hline Цинк & $0,64 \pm 0,16$ & $1,71 \pm 0,43$ & $8,16 \pm 2,04$ & $20,56 \pm 5,14$ & $10,14 \pm 2,54$ & 55 \\
\hline Кадмий & - & - & - & - & - & 0,5 \\
\hline Свинец & $0,25 \pm 0,06$ & 0,2 & $2,71 \pm 0,68$ & $0,69 \pm 0,17$ & $1,2 \pm 0,43$ & 32 \\
\hline \multicolumn{7}{|c|}{ Рецепторная точка № 6} \\
\hline Никель & - & - & - & - & - & 20 \\
\hline Марганец & $5,83 \pm 1,46$ & $25,30 \pm 6,33$ & $6,69 \pm 1,67$ & $6,72 \pm 1,68$ & $12,90 \pm 3,23$ & 1500 \\
\hline Медь & $0,23 \pm 0,06$ & $0,86 \pm 0,22$ & $0,52 \pm 0,16$ & $0,69 \pm 0,17$ & $0,76 \pm 0,17$ & 33 \\
\hline Цинк & $1,60 \pm 0,40$ & $41,65 \pm 10,41$ & $12,72 \pm 3,18$ & $9,01 \pm 2,25$ & $21,13 \pm 5,28$ & 55 \\
\hline Кадмий & - & - & - & - & - & 0,5 \\
\hline Свинец & $0,50 \pm 0,12$ & $1,39 \pm 0,35$ & $3,90 \pm 0,97$ & $0,51 \pm 0,13$ & $1,93 \pm 0,48$ & 32 \\
\hline
\end{tabular}

Примечания. Жирным шрифтом выделены превышения нормативов ПДК. «-» менее чувствительности прибора

\section{Результаты исслеАования}

Исследования, направленные на оценку содержания микроэлементов в почвах на территории Сибири и Дальнего Востока, проводятся уже более 40 лет[4]. Некоторыми учеными изучалось содержание в почвах тяжелых металлов [8]. В рамках исследования качества почвы в районах несанкционированных свалок аналогичный подход был использован при выборе приоритетных загрязняющих веществ. Результаты количественной оценки содержания тяжелых металлов в почвах с территории несанкционированных свалок представлены в таблице.

Результаты анализа показали, что единственным элементом, по которому наблюдаются превышения гигиенических нормативов на исследуемых участках, является цинк. Максимальное превышение норм ПДК по цинку было выявлено на свалке п. Батарейка (рецепторная точка № 1) - 3,5 ПДК на всём участке складирования отходов. По остальным химическим элементам превышения гигиенических нормативов в исследуемых образцах не наблюдалось. Концентрация никеля и кадмия в почве была настолько мала, что установить ее значение с помощью используемого метода и прибора не представлялось возможным. Однако сравнительный анализ содержания тяжелых металлов в образцах с территории свалок и в фоновой точке наглядно показал негативное воздействие несанкционированного складирования отходов. Во всех проанализированных рецепторных точках за исключением рецепторной точки № 2 (п. Кирзавод) наблюдалось превышение концен- 
трации тяжелых металлов на участках складирования отходов по сравнению с фоновыми показателями: выявлены превышения от 1,08 раз (по меди) до 15,84 раз (по цинку). Фоновые концентрации тяжелых металлов в рецепторной точке № 2, напротив, были выше аналогичных показателей с участка складирования отходов по никелю, марганцу, цинку и кадмию. Причиной высоких показателей концентрации некоторых тяжелых металлов в фоновой пробе может являться негативное воздействие промышленных выбросов, так как точка отбора прилегает к границе промплощадки ТЭЦ-1 и находится в зоне её влияния с подветренной стороны.

В процессе проведения исследования образцов почв на растровом электронном микроскопе JSM-6510LV JEOL было выявлено весовое содержание основных элементов в почве. Анализ результатов проведенного эксперимента показал, что значительного изменения концентрации основных элементов в фоновых пробах и в образцах с территории свалок не наблюдалось. Однако сравнительный анализ перечня выявленных элементов показал, что для проб, отобранных с участков несанкционированных свалок, характерен более расширенный перечень элементов по сравнению с фоном. Особенно ярко данная закономерность наблюдается в рецепторной точке № 6, где наличие соединений азота и фосфора, скорее всего, связано с по- ступлением в почву моющих средств совместно с жидкими бытовыми отходами.

В целом же указанный метод, на наш взгляд, не является показательным для исследования почвы, так как на качество проведения анализа значительное влияние оказывают, в первую очередь, маленький вес навески для исследования, а также гранулометрический состав отобранной пробы почвы, неравномерность ее состава по объему пробы.

\section{Зак^ючение}

Оценка содержания тяжелых металлов в почвах с территории несанкционированных свалок г. Улан-Удэ показала, что несанкционированное размещение отходов приводит к загрязнению почвы тяжелыми металлами. Однако не менее весомый вклад в загрязнение почвы вносят выбросы загрязняющих веществ в атмосферный воздух, в частности от предприятий теплоэнергетики.

В результате анализа весового содержания основных элементов в почве было выявлено, что для проб, отобранных с участков несанкционированных свалок, характерен более расширенный перечень элементов по сравнению с фоном.

\section{ЛИТЕРАТУРА}

1. Белоголовов В.Ф. 1989. Геохимический атлас Улан-Удэ. Улан-Удэ: Бурятское кн. изд-во. 51 с.

2. ГОСТ Р 53123-2008. Качество почвы. Отбор проб. Часть 5. Руководство по изучению городских и промышленных участков на предмет загрязнения почвы.

3. ГоСТ 17.4.4.02-2017. Охрана природы. Почвы. Методы отбора и подготовки проб для химического, бактериологического, гельминтологического анализа.

4. Макеев О.В. 1973. Микроэлементы в почвах Сибири и Дальнего Востока. М.: Наука. 174 с.

5. РД 52.18.191-89 Методические указания. Методика выполнения измерений массовой доли кислоторастворимых форм металлов (меди, свинца, цинка, никеля, кадмия) в пробах почвы атомно-абсорбционным анализом.

6. Руководство по санитарно-химическому исследованию почвы / Под ред. Подуновой А.Г., М. 1993.

7. Сеничкина М.Г. 1986. Микроэлементы в почвах Сибири. Новосибирск: Наука. 174 с.

8. Сосорова С.Б., Кашин В.К. 2009. Тяжелые металлы в почвах и растениях дельты реки Селенги. Улан-Удэ: Изд-во БНЦ СО РАН. 162 с.

9. Убугунов В.Л. 2004. Тяжелые металлы в садово-огородных почвах и растениях г. Улан-Удэ. Улан-Удэ: Изд-во БНЦ СО РАН. 128 с.

10. Убугунов Л.Л., Убугунов В.Л. 2013. Техногенное загрязнение почв Бурятии тяжелыми металлами: источники, современное состояние, ремедиация // Международный журнал прикладных фундаментальных исследований. № 8-1. С. 19-21.

11. Чередова Т.В., Чудинова 0.Н., Гулгенов С.Ж. 2018. Оценка биологической активности почв на несанкционированных свалках г. Улан-Удэ // Инновационные подходы к решению проблем «Сендайской рамочной программы по снижению риска бедствий на 2015-2030 годы»: сборник материалов международной научно-практической конференции, 19-20 октября 2018 г. Казань: Изд-во КНИТУ-КАИ. С. 346-350

๑ Чередова Татьяна Викторовна ( cheredova-tv@yandex.ru ), Чудинова Ольга Николаевна ( chudinova1980@inbox.ru ), Гулгенов Сергей Жаргалович ( gulgenov-s@mail.ru ), Воронина Юлия Сергеевна ( u_voronina96@mail.ru ).

Журнал «Современная наука: актуальные проблемы теории и практики» 